\title{
School-based supervised therapy programs to improve asthma outcomes: current perspectives
}

\author{
Guadalupe Salazar \\ Geeta Tarwala \\ Marina Reznik \\ Division of Academic General \\ Pediatrics, Children's Hospital at \\ Montefiore, Albert Einstein College of \\ Medicine, Bronx, NY, USA
}

This article was published in the following Dove Press journal: Journal of Asthma and Allergy

Correspondence: Marina Reznik

Children's Hospital at Montefiore, 34 I I

Wayne Ave, 8th Floor, Bronx, NY 10467 ,

USA

Tel + I 7I8 74I 2494

Fax + I 7184055260

Email mreznik@montefiore.org
Background: Asthma is one of the most common chronic diseases of childhood affecting 6.2 million ( $8.4 \%$ ) children ( $<18$ years old) in the USA. Asthma is also a leading cause of school absenteeism. Daily administration of preventive asthma medications improves asthma control. However, poor medication adherence is one of the barriers in achieving improved asthma outcomes. School-based supervised asthma therapy programs have been implemented to address this barrier.

Objectives: To conduct a review of the literature on school-based supervised asthma therapy interventions and the effect on outcomes in children with persistent asthma.

Methods: We conducted a literature search using electronic search engines (ie, PubMed and Cochrane) and combinations of different search terms "school-based asthma," "schoolbased asthma therapy," and "school-based supervised asthma therapy." Inclusion criteria were school-based interventions with supervised asthma medication administration conducted in the USA, measuring asthma outcomes. From 443 titles and abstracts, 9 studies met the inclusion criteria.

Results: School-based interventions with supervised asthma medication administration revealed improvement in asthma outcomes, including improved medication adherence, increased symptomfree days, decreased daytime and nighttime symptoms, decreased use of rescue medication, decreased asthma-related health care utilization, fewer exacerbations requiring treatment with prednisone, decreased school absenteeism due to asthma, fewer days of activity limitation, improved quality of life, and improvement in both pulmonary inflammatory markers and peak flow readings. Conclusion: Our literature review demonstrated that school-based supervised asthma therapy improves asthma outcomes in urban children with persistent asthma. Schools are an ideal setting for implementation of asthma interventions for children and adolescents.

Keywords: directly observed therapy, inhaled corticosteroids, medication adherence, interventions, children, schools

\section{Introduction}

Asthma is one of the most common chronic diseases of childhood in the US, disproportionately affecting inner-city children of color. ${ }^{1}$ According to 2015 US Centers for Disease Control and Prevention (CDC) Data, 6.1 million (8.3\%) of children under the age of 18 have asthma. ${ }^{2}$ Asthma is also a leading cause of school absenteeism, with $49 \%$ of US children with asthma reporting 1 or more asthma-related missed school days, which approximates to 13.8 million days per year. ${ }^{3}$ In 2007 , the annual economic cost of asthma, including medical costs and lost school and work days, accounted for more than $\$ 56$ billion. ${ }^{4}$ 
Daily administration of inhaled corticosteroids (ICS) is recommended by the national asthma guidelines and has been shown to improve asthma control for children with persistent asthma. ${ }^{5}$ Despite the national asthma guideline recommendations and the availability of safe and effective preventive medications, asthma remains a major cause of morbidity among children. Factors that influence asthma morbidity include improper medication administration technique and poor ICS medication adherence, which can lead to more frequent asthma attacks and increased emergency health care utilization and hospitalizations. ${ }^{6}$ Identifying barriers to proper medication administration and adherence along with providing asthma management support can improve health outcomes for children with persistent asthma.

The majority of US school-aged children spend one-third (6-7 hours per day) of their weekday at school during a school year. ${ }^{7}$ This makes schools a valuable setting to implement interventions to address medication administration and adherence barriers. As schools already have systems in place to provide daily medication for conditions like diabetes ${ }^{8}$ and attentiondeficit hyperactive disorder, ${ }^{9}$ implementing supervised preventive medication administration therapy for asthma can be a feasible intervention approach, especially among children who have poor asthma outcomes because of nonadherence. Several school-based asthma intervention programs tested the effects of the directly observed therapy (DOT) on asthma outcomes. The aim of this review is to examine evidence for the effectiveness of these programs on asthma outcomes in urban children.

\section{Methods}

\section{Search methodology}

We sought published intervention studies which evaluated outcomes in urban children who received supervised asthma therapy at school. A literature search was performed, setting the time frame of the search from the oldest article available (September 1980) to February 14th, 2018, when the final search was conducted. We searched 2 electronic databases, PubMed and the Cochrane Clinical Trials, using different combination of the search terms "school-based," "asthma," "therapy," and "supervised." References for included studies and relevant reviews that we encountered were checked to capture additional studies of interest. Weekly PubMed e-mail updates on new publications on topics related to asthma research were also reviewed.

\section{Inclusion criteria}

Studies (published up to February 14th, 2018) were included if they met the following criteria: 1) studies were published in English and conducted in US; 2) participants were schoolaged, urban children with asthma, from preschool to 12th grade; 3 ) interventions involved the supervised administration of preventive asthma medication in the school setting; and 4) reported asthma-related outcomes.

\section{Article selection}

We used different combinations of the following search terms: "asthma," "school-based," "supervised," and "therapy." Our first search term combination, "school-based asthma" yielded 322 articles through PubMed and 120 trials through the Cochrane database (Figure 1). A second key term combination, "school-based asthma therapy," resulted in 196 PubMed articles and 30 Cochrane trials. Our final key term combination, "school-based supervised asthma therapy," resulted in 5 PubMed articles and 7 Cochrane trials. The latter 2 searches populated articles and trials which were included in the original search under the "school-based asthma" search term combination. A total of 442 potentially eligible tiles and abstracts were identified. One additional article was identified through the weekly PubMed e-mail updates. ${ }^{10}$

Further review of identified articles and trials was performed using a 3-step process to assess inclusion and exclusion (Figure 1). In the first step, we screened articles by the title and abstract. Of the 443 titles and abstracts found, 420 were excluded due to not meeting inclusion criteria or being duplicates, leaving 23 articles. The second step was to review the full text of the 23 articles to determine alignment with the inclusion criteria. This yielded 9 full articles to be included in our study analysis. We completed a final third step of reviewing the bibliographies of articles that met our criteria; no new articles were identified.

\section{Results}

\section{Results of the search}

A total of 443 potentially eligible titles and abstracts were identified from database searches, search of reference lists of included studies, and weekly PubMed e-mail updates (Figure 1). Of these, 80 articles were excluded due to being duplicates, 230 articles were excluded after title review as the title did not mention any treatment intervention for asthma at school, 23 articles were excluded as they were non-US studies, and 80 were excluded after reading the abstract. Seven articles were excluded as full article was not available (conference abstracts), leaving 23 articles. After a full text review, 9 articles met eligibility criteria and were included in the review. 
Identification

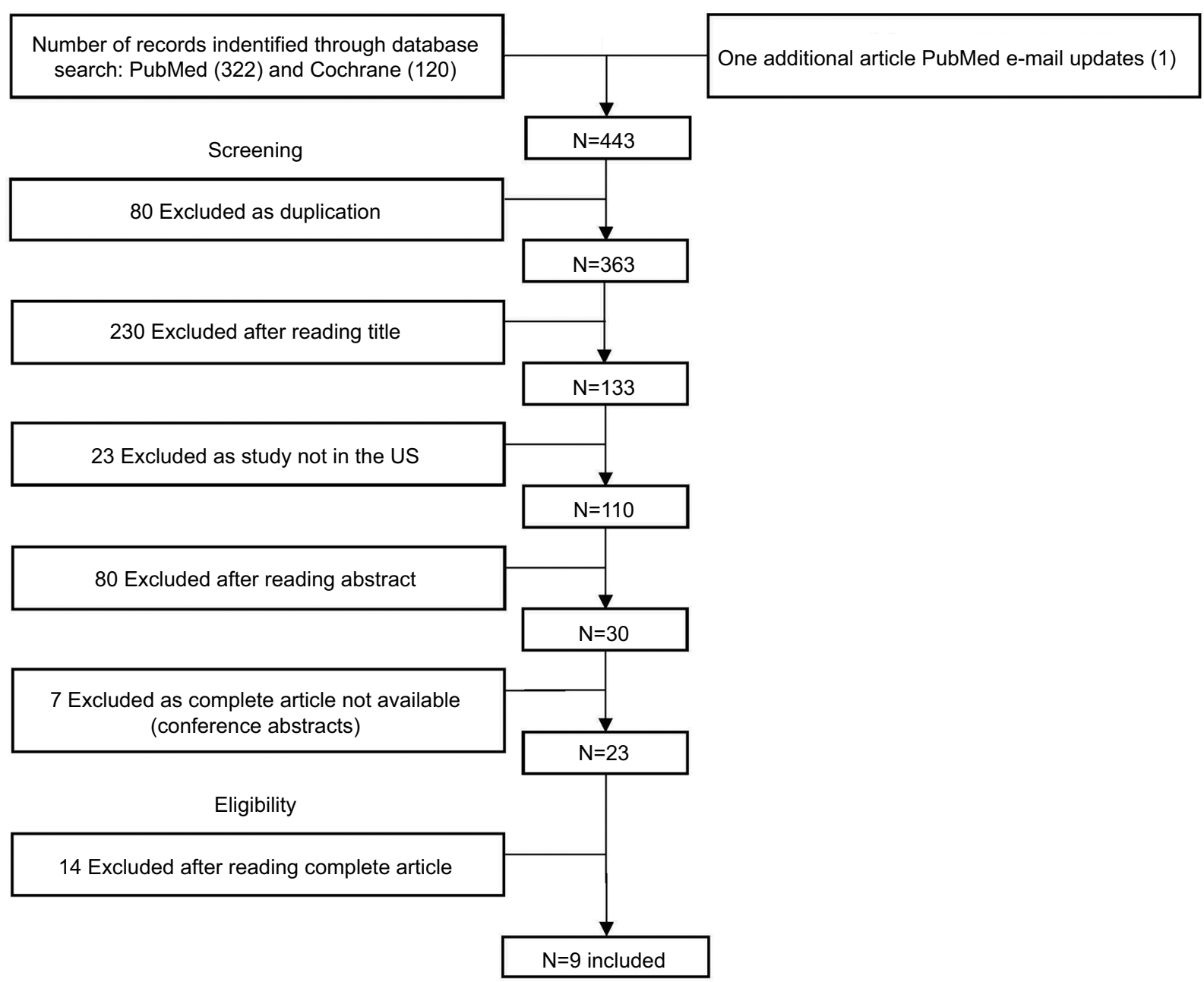

Figure I Results of the literature review using the PubMed and Cochrane databases.

\section{Characteristics of the studies}

Tables 1 and 2 describe characteristics of the 9 included studies, their intervention components, and main study outcomes. Although the search was done from the oldest article available on PubMed and Cochrane, the oldest article which met our inclusion criterion was from 2004 as DOT programs started in the past decade. All studies were conducted in the US - 5 in New York State, ${ }^{11-15} 1$ in Washington DC, ${ }^{16} 1$ in Alabama, ${ }^{17}$ 1 in Massachusetts, ${ }^{10}$ and 1 in Texas. ${ }^{18}$ All studies were conducted in urban populations. ${ }^{10-18}$ In terms of study design, 7 studies were randomized controlled trials (RCTs), ${ }^{11,12,14-18} 1$ was a retrospective study, ${ }^{10}$ and 1 used a pre-post design. ${ }^{13}$ All studies were conducted in school settings, with children and teens between the ages of 3 and 18 with persistent asthma as study participants. In terms of subject recruitment, 6 studies recruited children through schools, ${ }^{11-15,18} 2$ recruited through clinics, ${ }^{10,16}$ and 1 study recruited through schools, the health department, and directly through a physician's office. ${ }^{17}$ All 9 study interventions involved the implementation of a school-based, directly observed asthma preventive medication administration program. ${ }^{10-18} \mathrm{~A}$ single dose of ICS was administered daily at school in all interventions, except for 2 studies: 1) by Millard et al, ${ }^{18}$ in which 2 doses of ICS were given - one upon school arrival and a second dose before leaving school and 2) by Trivedi et al, ${ }^{10}$ where the child was given twice-daily dosing if needed. In addition to implementing supervised asthma therapy programs, supplemental interventions were concurrently integrated in 4 studies, including a tobacco reduction program for smoke-exposed children, ${ }^{14}$ counseling sessions incorporating motivational interviewing techniques, ${ }^{13}$ and peak flow meter monitoring. ${ }^{17,18}$ School-based telemedicine visits were conducted to ensure appropriate assessment, preventive medication prescription, and follow-up care in 1 study. ${ }^{12}$ Web-based technology was 


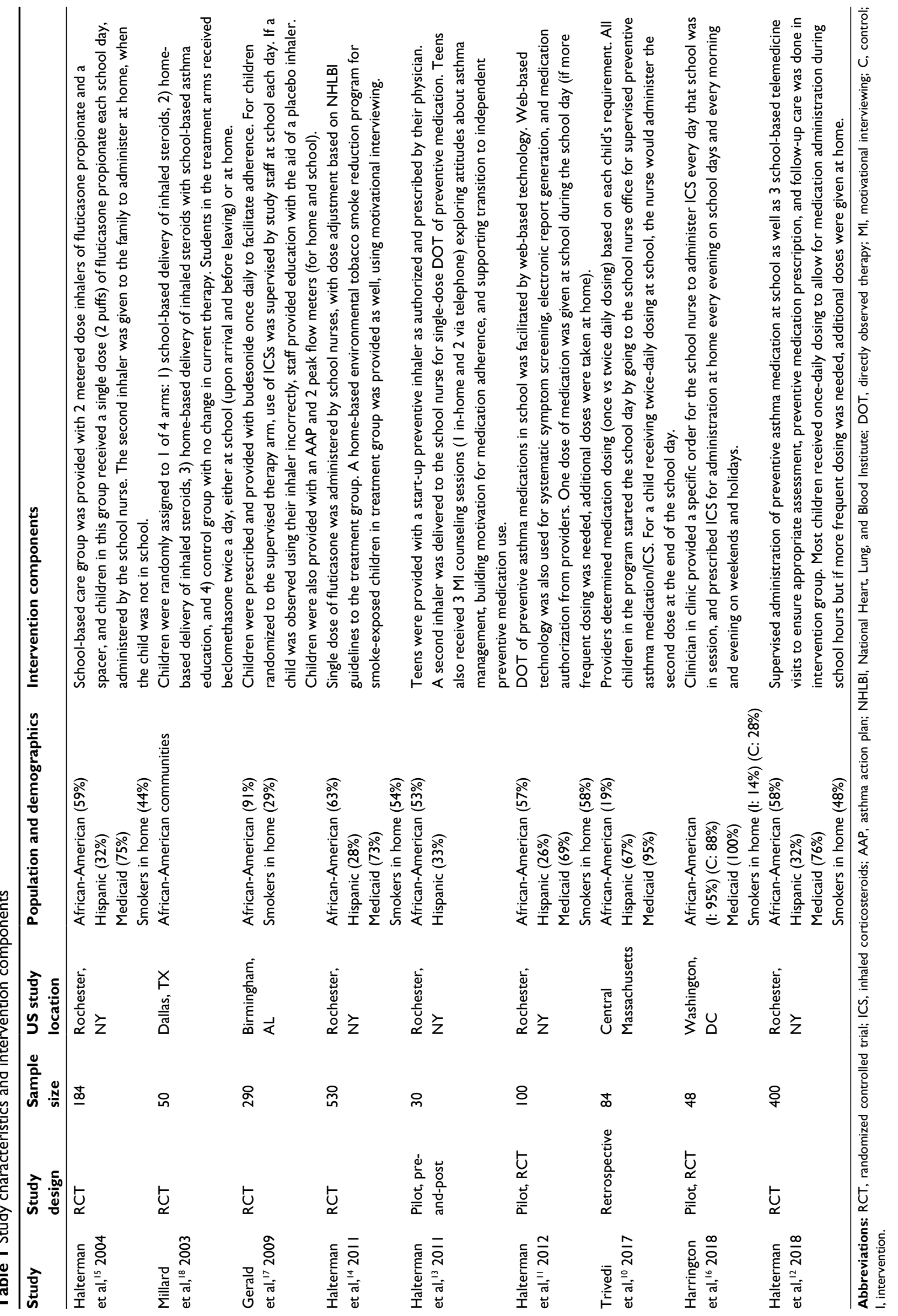


Table 2 Recruitment characteristics and study outcomes

\begin{tabular}{|c|c|c|c|c|}
\hline Study & $\begin{array}{l}\text { Recruitment } \\
\text { location }\end{array}$ & $\begin{array}{l}\text { Intervention } \\
\text { duration }\end{array}$ & Setting & Age group \\
\hline $\begin{array}{l}\text { Halterman } \\
\text { et al, }{ }^{15} \\
2004\end{array}$ & School & $\begin{array}{l}\text { I school } \\
\text { year for } \\
2 \text { consecutive } \\
\text { school years }\end{array}$ & $\begin{array}{l}54 \text { schools and } \\
\text { preschools }\end{array}$ & $3-7$ years old \\
\hline $\begin{array}{l}\text { Millard } \\
\text { et al, }{ }^{18} \\
2003\end{array}$ & School & 14 weeks & $\begin{array}{l}8 \text { elementary } \\
\text { schools }\end{array}$ & $\begin{array}{l}5-12 \text { years old; } \\
\text { mean age: } \\
8.44 \text { years }\end{array}$ \\
\hline
\end{tabular}

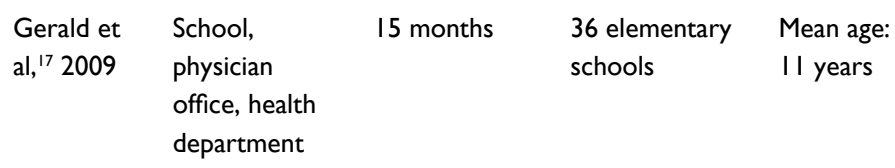

\begin{tabular}{|c|c|c|c|c|}
\hline $\begin{array}{l}\text { Halterman } \\
\text { et al, }{ }^{14}\end{array}$ & School & $\begin{array}{l}\text { I school } \\
\text { year for }\end{array}$ & $\begin{array}{l}67 \text { elementary } \\
\text { and preschools }\end{array}$ & $\begin{array}{l}\text { 3-10 years old; } \\
\text { mean age: }\end{array}$ \\
\hline 2011 & & $\begin{array}{l}3 \text { consecutive } \\
\text { school years }\end{array}$ & & 7.1 years \\
\hline
\end{tabular}

\begin{tabular}{|c|c|c|c|c|}
\hline $\begin{array}{l}\text { Halterman } \\
\text { et al, }{ }^{13}\end{array}$ & School & 6-8 weeks & $\begin{array}{l}\text { Rochester City } \\
\text { School District }\end{array}$ & $\begin{array}{l}\text { I2-15 years old; } \\
\text { mean age: }\end{array}$ \\
\hline 2011 & & & & I 3.6 years \\
\hline
\end{tabular}

\begin{tabular}{|c|c|c|c|c|}
\hline $\begin{array}{l}\text { Halterman } \\
\text { et al," }\end{array}$ & School & I school year & $\begin{array}{l}19 \text { elementary } \\
\text { and preschools }\end{array}$ & $\begin{array}{l}3-10 \text { years old; } \\
\text { mean age: }\end{array}$ \\
\hline 2012 & & & & 7.2 years \\
\hline
\end{tabular}

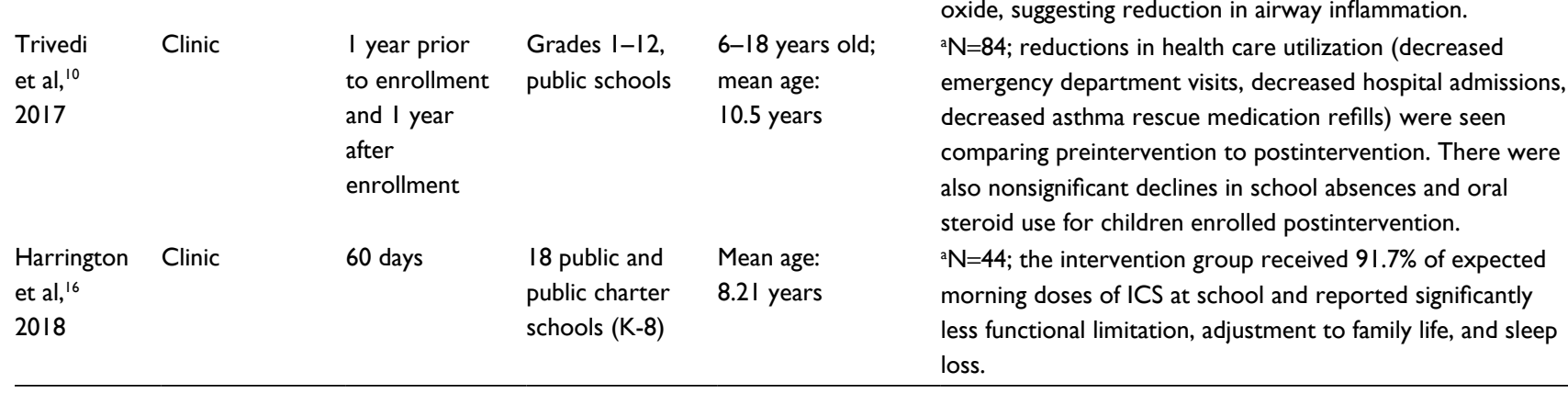

(Continued) 
Table 2 (Continued)

\begin{tabular}{|c|c|c|c|c|c|}
\hline Study & $\begin{array}{l}\text { Recruitment } \\
\text { location }\end{array}$ & $\begin{array}{l}\text { Intervention } \\
\text { duration }\end{array}$ & Setting & Age group & Study outcomes \\
\hline $\begin{array}{l}\text { Halterman } \\
\text { et al, }{ }^{12} \\
2018\end{array}$ & School & $\begin{array}{l}\text { I school } \\
\text { year for } \\
4 \text { consecutive } \\
\text { school years }\end{array}$ & $\begin{array}{l}49 \text { elementary } \\
\text { schools }\end{array}$ & $\begin{array}{l}3-10 \text { years old; } \\
\text { mean age: } \\
7.8 \text { years }\end{array}$ & $\begin{array}{l}\text { a } \mathrm{N}=400 \text {; children in the intervention group had more SFDs } \\
\text { per } 2 \text { weeks postintervention compared with children in } \\
\text { the enhanced usual care group. In addition, children in the } \\
\text { intervention group were less likely to have an emergency } \\
\text { department visit or hospitalization for asthma. }\end{array}$ \\
\hline
\end{tabular}

Notes: ${ }^{\mathrm{N}} \mathrm{N}=$ the number of subjects who completed the study.

Abbreviations: ICS, inhaled corticosteroids; SFD, symptom-free day; EPAC, episode of poor asthma control.

utilized in 2 studies. ${ }^{11,17}$ Gerald et a ${ }^{17}$ developed a web-based data collection system to record asthma symptoms and peak flow meter readings. Halterman et $\mathrm{a}^{11}$ utilized web-based technology for systematic symptoms screening, electronic report generation, and medication authorization from providers. Of note, the included effect estimates for observed health outcomes were drawn from the original study manuscripts and do not reflect a pooled analysis.

\section{Study outcomes}

\section{Medication adherence}

All 9 studies improved adherence as a result of the schoolbased, directly observed ICS administration intervention this is reflective of the school-based administration and does not account for adherence outside of the school setting. ${ }^{10-18}$ Only Halterman et $\mathrm{l}^{13}$ sought to measure teen's confidence, importance, and motivation with regard to self-administration and adherence to preventive medication through the use of a 10-point survey scale. As compared to the baseline, at the 2-month time point, teens reported greater confidence in their ability to take their preventive medication daily as prescribed (6.17 points at baseline vs 6.98 points at 2 months, $P=0.048$ ), greater perceived importance of taking their preventive medications for asthma control (8.01 vs 9.04 points, $P=0.012$ ), and greater motivation to take these medications daily (6.11 vs 7.37 points, $P=0.043) .{ }^{13}$ Significant improvement was seen in motivation to take daily preventive medication at the final assessment as well (6.11 points at baseline vs 7.81 points at final assessment, $P=0.043) .{ }^{13}$ In Harrington et al, ${ }^{16}$ the adjusted overall proportion of expected total doses of morning ICS administered at school by school nurses in the intervention group was $91.7 \%$, which exceeded the hypothesized rate of $80 \%$, highlighting successful implementation.

\section{Symptom-free days (SFDs) and daytime and nighttime symptoms}

Seven studies reported improvement in daytime as well as nighttime symptoms postintervention. ${ }^{11-15,17,18}$ Children in the school-based care group experienced more SFDs during the early winter months than the usual-care group ( 9.2 vs 7.3 days per 2 weeks, $P=0.02) .{ }^{15}$ Similar findings were observed in Halterman et al's ${ }^{12-14}$ subsequent studies: 1) 11.6 vs 10.7 days per 2 weeks in peak winter season $\left.(P<0.001),{ }^{14} 2\right) 11.6$ vs 10.97 days per 2 weeks $(P=0.01),{ }^{12}$ and 3) 8.71 days at baseline vs 10.79 days at 2 months vs 12.89 days per 2 weeks at final assessment $\left(P=0.046\right.$ and $P=0.004$, respectively). ${ }^{13}$ Decreased episodes of nocturnal awakening with asthma symptoms were observed by Millard et $\mathrm{al}^{18}\left(\chi^{2}=7.641, d=2\right.$, $P=0.022)$ and Halterman et al ${ }^{11,14}(1.7$ vs 2.3 nights per 2 weeks during peak winter season, $P<0.001$ ), ${ }^{14}$ (1.52 vs 2.34 nights per 2 weeks, $P=0.023) .{ }^{11}$ This can translate to less sleep loss due to asthma, as observed by Harrington et a ${ }^{16}$ at the end of the 60-day study period (1.7 vs 4.1 nights per 2 weeks, $P=0.04)$. In Gerald et al, ${ }^{17}$ the odds of experiencing an episode of poor asthma control (EPAC) during the baseline period were 1.57 times the odds of experiencing an EPAC during the follow-up period $(90 \% \mathrm{CI}, 1.20,2.06, P=0.006)$ in supervised therapy group; there was no difference in the likelihood of an EPAC between the baseline and follow-up period in the usual-care group. An EPAC was defined as 1 or more of the following each month: 1) an absence from school due to respiratory illness or asthma; 2) average use of rescue medication more than 2 times per week (not including pre-exercise treatment); or 3) at least 1 red or yellow peak flow meter reading. ${ }^{17}$

\section{Use of rescue medication}

Six studies found significant differences in the frequency of rescue medication use between the intervention and control groups. ${ }^{10,11,13-15,18}$ In Halterman et al, ${ }^{15}$ those children in the school-based care group not exposed to smoke had significantly fewer days requiring rescue medications when compared to the usual-care group (1.6 vs 2.3 days per 2 weeks, $P=0.03)$. In Millard et al, ${ }^{18}$ significant differences were found by week 5 in frequency of bronchodilator use $\left(\chi^{2}=7.411, d f=2, P=0.025\right)$; in Halterman et al, ${ }^{11}$ treatment 
children experienced fewer days requiring rescue medications ( 1.66 vs 2.44 days per 2 weeks, $P=0.012$ ). In 2 other studies by Halterman et al, days with rescue medication use per 2 weeks were 1.6 in the treatment group as compared to 2.6 in control group $(P<0.001),{ }^{14}$ and teens reported fewer days using rescue medication (2.54 days at baseline vs 0.50 days at final assessment over past 2 weeks, $P=0.015) .{ }^{13}$ In terms of rescue medication refills, Trivedi et $\mathrm{al}^{10}$ observed a $46.3 \%$ decrease between the pre- and postintervention periods $(P<0.001)$.

\section{Health care utilization}

Four studies observed less health care utilization, which may translate to a decrease in cost and disease burden. ${ }^{10,12,15,18}$ Health care utilization includes emergency department visits, ambulatory visits, hospitalizations, and urgent care visits. In Halterman et al, ${ }^{12}$ children receiving the intervention were less likely to have an emergency department visit or hospitalization for asthma compared with children in the enhanced usual care (eUC) group ( $7 \%$ vs $15 \%$, odds ratio [OR], 0.52; 95\% CI, 0.32-0.84). Trivedi et al ${ }^{10}$ observed a decrease in asthma-related ED visits from a preintervention mean of 0.8 to 0.3 visits per year, postintervention $(P<0.001)$, and a decrease in asthma-related hospitalizations from a preintervention mean of 0.3 admissions to 0 per year $(P<0.001)$. In terms of asthma-related acute clinic visits, Halterman et $\mathrm{al}^{15}$ noted that those children receiving school-based care and not exposed to smoke were less likely to have had 3 or more acute visits for asthma as compared to the usual-care group (6 [13\%] of 47 children vs 17 [31\%] of 54 children, $P=0.03$ ). Millard et $\mathrm{al}^{18}$ further observed a decrease in asthma-related visits to physicians as well $\left(\chi^{2}=7.641, d f=2, P=0.022\right)$.

\section{Prednisone administration}

One study by Halterman et $\mathrm{al}^{14}$ concluded that children receiving the school-based supervised asthma therapy were less likely than those in the usual-care group to have an asthma exacerbation requiring prednisone treatment (31 visits [12\%] vs 49 visits [18\%], respectively, $P=0.05$ ).

\section{School absenteeism}

Four studies showed that children in the school-based care group missed less school because of asthma when compared to the usual-care group. ${ }^{13-15,18}$ In 3 studies by Halterman et al, ${ }^{11,14,15}$ findings included the following: 1) $6.8 \mathrm{vs}$ 8.8 days missed per school year $\left.(P=0.047),{ }^{15} 2\right) 0.37$ vs 0.85 days missed per 2 weeks $(P=0.034),{ }^{11}$ and 3$) 0.3$ vs 0.5 days missed per 2 weeks $(P=0.002) .{ }^{14}$ In Millard et al, ${ }^{18}$ children were randomly assigned to 1 of 4 arms: 1) school-based delivery of inhaled steroids, 2) home-based delivery of inhaled steroids, 3) home-based delivery of inhaled steroids with school-based asthma education, and 4) control group with no change in current therapy; school attendance was 91\% for school-based group, 85\% for home-based group (groups 2 and 3 were later combined, as no parent attended more than 1 of the 4 education sessions provided to group 3 ), and $77 \%$ for control group (with statistically significant differences found between groups, $P<0.05)$.

\section{Days of activity limitation}

Four studies found that subjects experienced less activity limitation due to asthma postintervention. ${ }^{11,13,14,16}$ In 2 studies by Halterman et al, ${ }^{11,14}$ the treatment group reported fewer days of activity limitation per 2 weeks as compared to control group (1.3 vs 1.8 days, $P=0.003),{ }^{14}$ (1.21 vs 2.04 days, $P=0.043) .{ }^{11}$ In another study by Halterman et al, ${ }^{13}$ as compared to baseline values, teens reported fewer days of activity limitation per 2 weeks at 2-month assessment (2.93 vs 0.89 days, baseline vs 2 -month, respectively, $P=0.01$ ). In Harrington et al, ${ }^{16}$ intervention subjects reported significantly less functional limitation $(42.9 \%$ vs $73.9 \%, P=0.04)$.

\section{Quality of life}

Three studies evaluated quality of life, ${ }^{13,15,16}$ in a study by Halterman et al, ${ }^{15}$ caregivers of children in the school-based care group had a greater improvement in quality of life compared with caregivers of children in the usual-care group ( 0.63 vs 0.24 change score, $P=0.047)$. In another study by Halterman et al, ${ }^{13}$ teens reported significant improvement in quality of life at both 2-month and final assessment time points when compared to baseline $(4.80,5.68$, and 6.19 , for baseline, 2-month, and final assessment, respectively, $P=0.001$ and $P=0.004$ ) on a 7-point scale. In Harrington et al, ${ }^{16}$ patients receiving the intervention reported fewer adjustments to family life to accommodate asthma-related events $(23.8 \%$ vs $56.5 \%, P=0.03)$.

\section{Pulmonary inflammatory markers}

Biochemical markers (nitric oxide levels as indicator of inflammation) were measured and evaluated in 3 studies by Halterman et al. ${ }^{11-13}$ Exhaled nitric oxide levels significantly decreased from baseline to the 2-month assessment (28.71 vs $25.61 \mathrm{ppb}, P=0.012) .{ }^{13}$ Significant change in exhaled nitric oxide levels was also observed ( -9.62 to $-0.39 \mathrm{ppb}$, $P=0.033),{ }^{11}$ suggesting improvement in airway inflammation. Children in the intervention group had a greater decline in 
fractional nitric oxide level as compared to children in eUC (mean difference, $-5.54 ; 95 \% \mathrm{CI},-9.8$ to -1.3 ). ${ }^{12}$

\section{Peak flow}

Peak flow measurements (volume per second) were conducted by Millard et al, ${ }^{18}$ which showed higher peak flow readings for the treatment group, suggesting less inflammation and narrowing of airways. By the end of the first week, average peak flow readings were already significantly higher for the home and school medication administration groups when compared to the control group $(F[2,39]=3.312$, $P=0.047)$. Those higher peak flow values were maintained throughout the study.

\section{Discussion}

All 9 studies $^{10-18}$ included in this literature review showed improved asthma outcomes. Seven of these studies measured asthma symptoms, and study results showed improvement in SFDs and daytime and nighttime symptoms. ${ }^{11-15,17,18}$ Studies reported decrease in both rescue medication use and health care utilization. ${ }^{10-15,18}$ Improvement in quality of life was also observed as reported by caregivers and teens. ${ }^{13,15,16}$ These results indicate that supervised asthma medication administration at schools can be a feasible way to reduce asthma morbidity and address the issues of nonadherence commonly contributing to morbidity in children with persistent and uncontrolled asthma. The integration of care coordination between physician, family, and school is vital for the asthma management of children with persistent asthma. ${ }^{11}$

Though successful, several barriers were encountered when implementing these interventions. Not all schools have a full-time school nurse available and the public school system's current burden of demands for time and resources presents a significant constraint. ${ }^{19}$ Medication administration by school nurses results in an increased, uncompensated workload for the school nurses..$^{20}$ Though many US school districts are facing the burden of financial strain and limited resources, schools with limited health personnel are able to regularly administer daily preventive medications for other conditions (eg, attention-deficit hyperactivity disorder), attesting to the feasibility of establishing simple systems to improve medication adherence. ${ }^{11}$ In Halterman et al, ${ }^{11}$ an asthma care coordinator, a registered nurse with additional training in childhood asthma, was appointed to maintain communication between caregiver, physician, and school health staff. An asthma care coordinator can assist the school nurse serving as a liaison between families, physicians, and schools. This person could offer encouragement and support to the family of a student with asthma and promote ongoing communication between the family, physician, and school nurse to optimize asthma management. Programs can also be made more feasible if initiation of intervention starts at the physician's office for children who already have a physician, decreasing the burden on school nurses by automatically faxing or electronically transmitting a medication administration form to the school, allowing administration of ICS for children who may benefit from supervised therapy. Integrating health care provider and school electronic health record systems could further decrease the workload of school nurse; if the medical provider decides to step-up in therapy due to persistent or worsening symptoms, a new treatment plan would be sent directly to the school nurse. With the current advancement of technologies, electronic means of monitoring such as remote dose counters or forced expiratory volume in 1 second monitoring can alleviate the need for in-person monitoring of ICS and rescue medication use for asthma. Ease of implementation, generalizability, and sustainability are key to the development of such partnerships between the health care system and school nurses.

The 9 studies included in this review have several strengths. Out of 9 studies, 7 studies utilized a rigorous RCT study design ${ }^{11,12,14-18}$ and 5 studies had sample sizes $\geq 100 .^{11,12,14,15,17}$ Seven studies were conducted over 1 or more school years. ${ }^{10-15,17}$ Asthma education programs were incorporated in 6 studies. ${ }^{11-13,16-18}$ Analysis of peak flow ${ }^{17,18}$ and nitric oxide ${ }^{11-13}$ served as more objective indicators of asthma improvement than caregiver self-report.

This literature review has a few limitations to consider. We were not able to account unpublished studies as the results are not available, resulting in potential bias. All studies included were conducted in urban minority population of children where prevalence of asthma is high and medication adherence is poor; we are unable to generalize the same results and interventions needed for other populations living in suburban and rural communities. As caregiver consent was required for all studies, consenting bias could have directly influenced implementation success, as caregivers who consent may be more proactive in taking action to help improve their child's asthma management. Blinding of caregivers, participants, school nurses, and physicians was not possible, which could further have affected the results of studies. Studies did not evaluate adherence preintervention, which could have provided insight in terms of percentage of improvement postintervention. There was no control group in 2 studies. ${ }^{10,13}$ There was no true control group in the remaining studies children in the eUC group may have had improved outcomes 
simply by participating in the trial, creating a conservative bias. ${ }^{11,12,14-18}$ In 7 studies, physicians were aware of participation in control group, indirectly alerting them to address the child's asthma. ${ }^{10,12-15,17,18}$

In all studies, supervised medication was given only on school days and no medication administration records were collected on weekends and holidays. ${ }^{10-18}$ In 5 studies, both groups received asthma education, resulting in potential intervention effects for both. ${ }^{11,12,16-18}$ To address the barrier of access to medication, Gerald et $\mathrm{al}^{17}$ provided medication to both groups, making it difficult to predict if improved adherence was due to medication availability. In Millard et al, ${ }^{18}$ none of the subjects were taking anti-inflammatory medication on a regular basis despite appropriate clinical indications - merely providing access to anti-inflammatory medication to be taken at home could compare favorably with school-based administration. As allergies, weather changes, and viral infections can trigger asthma attack symptoms, the studies might have been biased as they were all done during school year. ${ }^{21}$ Despite these limitations, reviewed studies found significant improvements in asthma outcomes in urban minority children, population disproportionately burdened by asthma and its morbidity.

Some intervention considerations can help make the programs providing supervised asthma medication administration more feasible and acceptable. Medication cost is a major barrier. In 7 studies, medication was purchased through the program funding, which increased the cost and decreased sustainability of these interventions. ${ }^{11-17}$ As majority of the population has a medical insurance coverage (eg, private, Medicaid), purchasing medication through the child's insurance can significantly decrease the cost of program. ${ }^{22}$

School nurse asthma training is important for asthma program implementation. Each year, a mandatory district's school nurse meeting should be held just before the school year starts in order to train school nurses on the program's protocol. School nurses have the opportunity to teach proper inhaler and spacer technique, demonstrate use of a peak flow meter, motivate children to take their medications, and influence general self-management, both in school and at home. Asthma education for children, adolescents, and caregivers is crucial as well to improve medication adherence after the program ends. A medical provider or trained school nurse could lead education seminars and present on the importance of preventive asthma medication and proper use of ICSs for children with persistent asthma. Having a better understanding of the pathophysiology of asthma, common triggers, warning signs of an asthma attack, medication education (dose, time of administration, mechanism of action of preventive and rescue medicine, and difference between side effects of oral corticosteroids and ICS), and an asthma action plan can help correct false beliefs and improve asthma outcomes. Collaborative discussion and negotiation of the treatment plan between physicians, caregivers, and adolescent patients can also enhance adherence, setting goals and preferences for frequency of dosing (once a day or twice daily). Adolescents are in a stage of development that can allow them to uptake asthma self-management. ${ }^{23}$ If health educators, school nurses, and medical providers encourage this effectively, the support and resources provided can help adolescents reach this level of self-efficacy. ${ }^{23}$ Group workshops and coaching sessions with motivational interviewing could be especially beneficial for adolescents. Group workshops provide adolescents the opportunity to share the burden of their illness and to learn how others cope with asthma. ${ }^{23}$ Incorporating asthma education into the health curriculum at school can raise awareness about asthma and children with asthma may feel less hesitant or embarrassed to take medication at school. ${ }^{24}$ Families of smoke-exposed children should receive an environmental tobacco smoke reduction program aimed at motivating smoking cessation among family members and decreasing their child's exposure to environmental tobacco smoke. ${ }^{14}$

Establishing a structured and supervised daily routine of taking ICS which fits into existing lifestyle can improve medication adherence at home. Utilization of technology (eg, cell phone alarms, text messages, telemedicine) can be promising. Maintaining an asthma diary (documenting dose of preventive and/or rescue medication taken, daytime and nighttime symptoms [including coughing, wheezing, and shortness of breath], triggers aggravating asthma attack, visits to physician's office or emergency department for asthma attacks, any hospitalizations due to asthma, prescription refills, days of school missed because of asthma, side effects of medications) which is frequently checked by the school nurse and at the physician's office can help in understanding and managing the asthma more effectively. If the physician or school nurse feels that poor adherence is due to a lack of availability of medication, delivering medication directly from the pharmacy to home and school can help improve adherence. Novel methods for health care assessment and delivery, such as telemedicine, might represent a method to enhance both efficiency and sustainability of chronic disease care within schools.

Interventions to improve morbidity outcomes in poor, ethnic minority children are critically needed. Although 
the implementation of these school-based interventions has proven successful in improving health outcomes for these children with persistent asthma in urban, inner-city populations, there is an overarching question as to how this translates over to adherence outside of the school setting. As noted in our review, DOT programs automatically improve medication adherence in general as nurses would standardize the administration regime, but how does this impact asthma self-management? To analyze the effects that these interventions may have on self-management (either through the caregiver administering medications or teens administering themselves), adherence considerations would need to extend outside of school and into a home-based setting, looking at medication administration practices during evenings, weekends, and school vacation periods. Ways to start evaluating these effects could be to follow-up with participants who completed these interventions, analyzing postintervention health outcomes, and looking to examine if practices promoted by the intervention carried over to and were sustained outside of the school setting. Children need to learn responsibility and caregivers need to supervise and remind their children to take medication. It should also be noted that shifting the focus of responsibility for maintenance of asthma treatment to schools may also decrease caregiver sense of involvement in asthma care, increasing the likelihood of missed evening and weekend medication doses or inconsistent home monitoring of asthma symptoms. It may also decrease opportunities for titration of medication by decreasing necessary visits with their physicians, extending following periods.

In addition to the potential barrier of increased dependence on school administration shifting the focus of responsibility for self-maintenance of asthma, social determinants of health that influence these outcomes may remain unaddressed. Asthma is a chronic condition with is greatly affected by the environment, making this a mostly environmental disease. ${ }^{25}$ Though school-based programs would automatically ameliorate medication adherence and generally improve health outcomes, the underlying triggers that detrimentally affect urban populations could remain unresolved. This brings in the question what this means for health care - if entities increase the provision of medication without addressing core variables that increase morbidity (poor self-management practices and continued environmental detriments), there will be no progress and asthma will continue to persist as one of the most common chronic diseases of childhood.

\section{Disclosure}

The authors report no conflicts of interest in this work.

\section{References}

1. Center for Disease Control and Prevention. Summary Health Statistics: National Health Interview Survey. Atlanta, GA: Center for Disease Control and Prevention; 2015. Available from: https://ftp.cdc.gov/ pub/Health_Statistics/NCHS/NHIS/SHS/2015_SHS_Table_C-1.pdf. Accessed May 2, 2018.

2. Center for Disease Control and Prevention [webpage on the Internet]. National Current Asthma Prevalence: 2016. Atlanta, GA: Center for Disease Control and Prevention; 2018. Available from: https://www. cdc.gov/asthma/most_recent_data.htm. Accessed May 1, 2018.

3. Center for Disease Control and Prevention [webpage on the Internet]. Asthma-Related Missed School Days Among Children Aged 5-17 Years. Atlanta, GA: Center for Disease Control and Prevention; 2015. Available from: https://www.cdc.gov/asthma/asthma_stats/missing_days. htm. Accessed May 2, 2018.

4. United States Environmental Protection Agency. Asthma Facts. Washington, DC: United States Environmental Protection Agency; 2017. Available from: https://www.epa.gov/sites/production/files/2017-08/ documents/2017_asthma_fact_sheet.pdf. Accessed May 2, 2018.

5. National Asthma Education and Prevention Program. Expert Panel Report 3 (EPR-3): guidelines for the diagnosis and management of asthma-summary report 2007. J Allergy Clin Immunol. 2007;120(Suppl 5):S94-S138.

6. Reznik M, Silver EJ, Cao Y. Evaluation of MDI-spacer utilization and technique in caregivers of urban minority children with persistent asthma. J Asthma. 2014;51(2):149-154.

7. Swanbrow D. US children and teens spend more time on academics. Michigan News. University of Michigan; 2004. Available from: https:// news.umich.edu/u-s-children-and-teens-spend-more-time-on-academics/. Accessed May 1, 2018.

8. American Diabetes Association. State Laws, Regulations and Policies for School Diabetes care. Living with Diabetes. Arlington, VA: American Diabetes Association; 2017. Available from: http://www.diabetes.org/ living-with-diabetes/parents-and-kids/diabetes-care-at-school/legalprotections/state-laws-and-policies.html. Accessed May 2, 2018.

9. Dang MT, Warrington D, Tung T, Baker D, Pan RJ. A school-based approach to early identification and management of students with ADHD. J Sch Nurs. 2007;23(1):2-12.

10. Trivedi M, Patel J, Lessard D, et al. School nurse asthma program reduces healthcare utilization in children with persistent asthma. $J$ Asthma. 2017:1-7.

11. Halterman JS, Fagnano M, Montes G, et al. The school-based preventive asthma care trial: results of a pilot study. J Pediatr. 2012;161(6):1109-1115.

12. Halterman JS, Fagnano M, Tajon RS, et al. Effect of the School-Based Telemedicine Enhanced Asthma Management (SB-TEAM) program on asthma morbidity: a randomized clinical trial. JAMA Pediatr. 2018;172(3):E174938.

13. Halterman JS, Riekert K, Bayer A, et al. A pilot study to enhance preventive asthma care among urban adolescents with asthma. J Asthma. 2011;48(5):523-530.

14. Halterman JS, Szilagyi PG, Fisher SG, et al. Randomized controlled trial to improve care for urban children with asthma: results of the schoolbased asthma therapy trial. Arch Pediatr Adolesc Med. 2011;165(3): 262-268

15. Halterman JS, Szilagyi PG, Yoos HL, et al. Benefits of a school-based asthma treatment program in the absence of secondhand smoke exposure: results of a randomized clinical trial. Arch Pediatr Adolesc Med. 2004;158(5):460-467.

16. Harrington CB, Langhans E, Shelef DQ, Savitz M, Whitmore C, Teach SJ. A pilot randomized trial of school-based administration of inhaled corticosteroids for at-risk children with asthma. J Asthma. 2018;55(2):145-151. 
17. Gerald LB, Mcclure LA, Mangan JM, et al. Increasing adherence to inhaled steroid therapy among schoolchildren: randomized, controlled trial of school-based supervised asthma therapy. Pediatrics. 2009;123(2):466-474.

18. Millard MW, Johnson PT, Mcewen M, et al. A randomized controlled trial using the school for anti-inflammatory therapy in asthma. JAsthma. 2003;40(7):769-776.

19. National Association of School Nurses prepared by Burkhardt Research Services [webpage on the Internet]. School Nursing in the United States: Quantitative Study. Silver Spring, MD: National Association of School Nurses; 2007. Available from: http://arcadiantelepsychiatry. com/files/2007_Burkhardt_Report.pdf. Accessed May 1, 2018.

20. Bundy DG, Berkoff MC, Ito KE, Rosenthal MS, Weinberger M. Interpreting subgroup analyses: is a school-based asthma treatment program's effect modified by secondhand smoke exposure? Arch Pediatr Adolesc Med. 2004;158(5):469-471.
21. Center for Disease Control and Prevention [webpage on the Internet] Common Asthma Triggers. Atlanta, GA: Center for Disease Control and Prevention; 2012. Available from: https://www.cdc.gov/asthma/triggers. html. Accessed May 3, 2018.

22. Center for Disease Control and Prevention [webpage on the Internet]. Health Insurance Coverage. Atlanta, GA: Center for Disease Control and Prevention; 2017. Available from: https://www.cdc.gov/nchs/fastats/ health-insurance.htm. Accessed May 3, 2018.

23. Bruzzese JM, Bonner S, Vincent EJ, et al. Asthma education: the adolescent experience. Patient Educ Couns. 2004;55(3):396-406.

24. Walker TJ, Reznik M. In-school asthma management and physical activity: children's perspectives. J Asthma. 2014;51(8):808-813.

25. Kelly WF [webpage on the Internet]. Allergic and Environmental Asthma; 2017. Available from: https://emedicine.medscape.com/ article/137501-overview. Accessed May 1, 2018.
Journal of Asthma and Allergy

\section{Publish your work in this journal}

The Journal of Asthma and Allergy is an international, peer-reviewed open access journal publishing original research, reports, editorials and commentaries on the following topics: Asthma; Pulmonary physiology; Asthma related clinical health; Clinical immunology and the immunological basis of disease; Pharmacological interventions and

\section{Dovepress}

new therapies. This journal is included in PubMed. The manuscript management system is completely online and includes a very quick and fair peer-review system, which is all easy to use. Visit http://www. dovepress.com/testimonials.php to read real quotes from published authors. 